\title{
ON THE SECONDARY SEXUAL CHARACTERS OF NOTIOPHILUS.
} BY ROLAND HAYWARD, MILTON, MASS.

Some years ago I published a short note on the secondary sexual characters of the North American species of Omophron (Psyche, ix, p. 304), in which I referred to the dilatation of the first* joint of the middle tarsi in the males of a large majority of our species of that genus. Until a short time ago I was unaware of the occurrence of this character elsewhere in the Carabinæ, though quite frequently observable in several groups of the sub-family Harpalinæ.

My attention, however, was recently called by Mr. E. A. Schwarz to the fact that C. G. Thomson (Bull. Soc. Ent. France, 1883 , p. cxii) had pointed out that in three European species of Notiophilus (aquaticus Linn, palusiris Duft. and biguttalus Fab.) the first joint of the middle tarsi is dilated and spongy beneath in the males. I was thus led to an examination of the North American species. Males have been seen of all those known to occur within our faunal limits except aquaticuis Linn. and obscurus Fall. Based upon this character they may be divided into two groups. Of these the first contains aquaticus Linn., sylvaticus Esch., hardyi Putz. and nitens Lec., in all of which the basal joint is dilated in the males, and, in the first three at least, spongy beneath. Whether the latter character occurs in nitens I have been unable to ascertain, as the only specimen that I have been able to study, i. e.: Leconte's type, is so mounted that only the upper surface of the joint is visible; but in all probability it agrees with the other species. Although not seen by myself, I have included aquaticus on 'Thomson's authority. In the second series the joint is simple as in the females. Here are included eneus Hbst., semiopacus Esch., semistriatus Say and sibiricus Mots.

The tarsi are but narrowly dilated in the males of all our species. This applies to the anterior tarsi as well as to the basal joint of the middle pair.

M. Pierre Lesne (Bull. Soc. Ent. France, $\mathbf{1} 888$, p. clxv) calls attention to a character common to many Carabidæ which he has observed in the European species of Notiophilus, i. e.: that the anal segment has one setigerous puncture each side at tip in the males, two in the females. This applies to all the species of our fauna that I have seen. Of nitens the male alone is known to me, in which the anal segment is unisetose each side. Aquaticus and obscurus are both unknown to me in nature.

*Erroneously printed "second," but corrected ibid, p. 335 . 

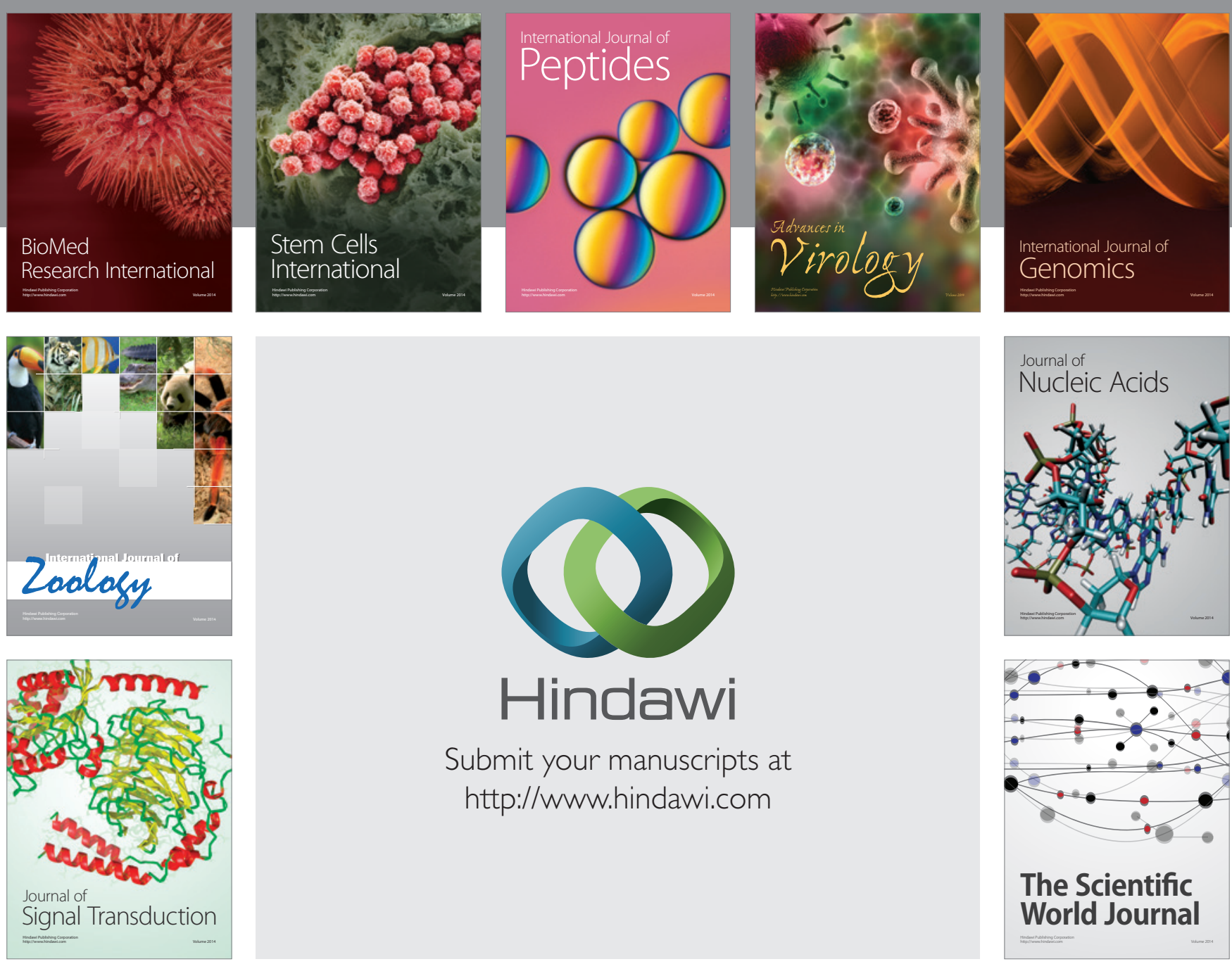

Submit your manuscripts at

http://www.hindawi.com
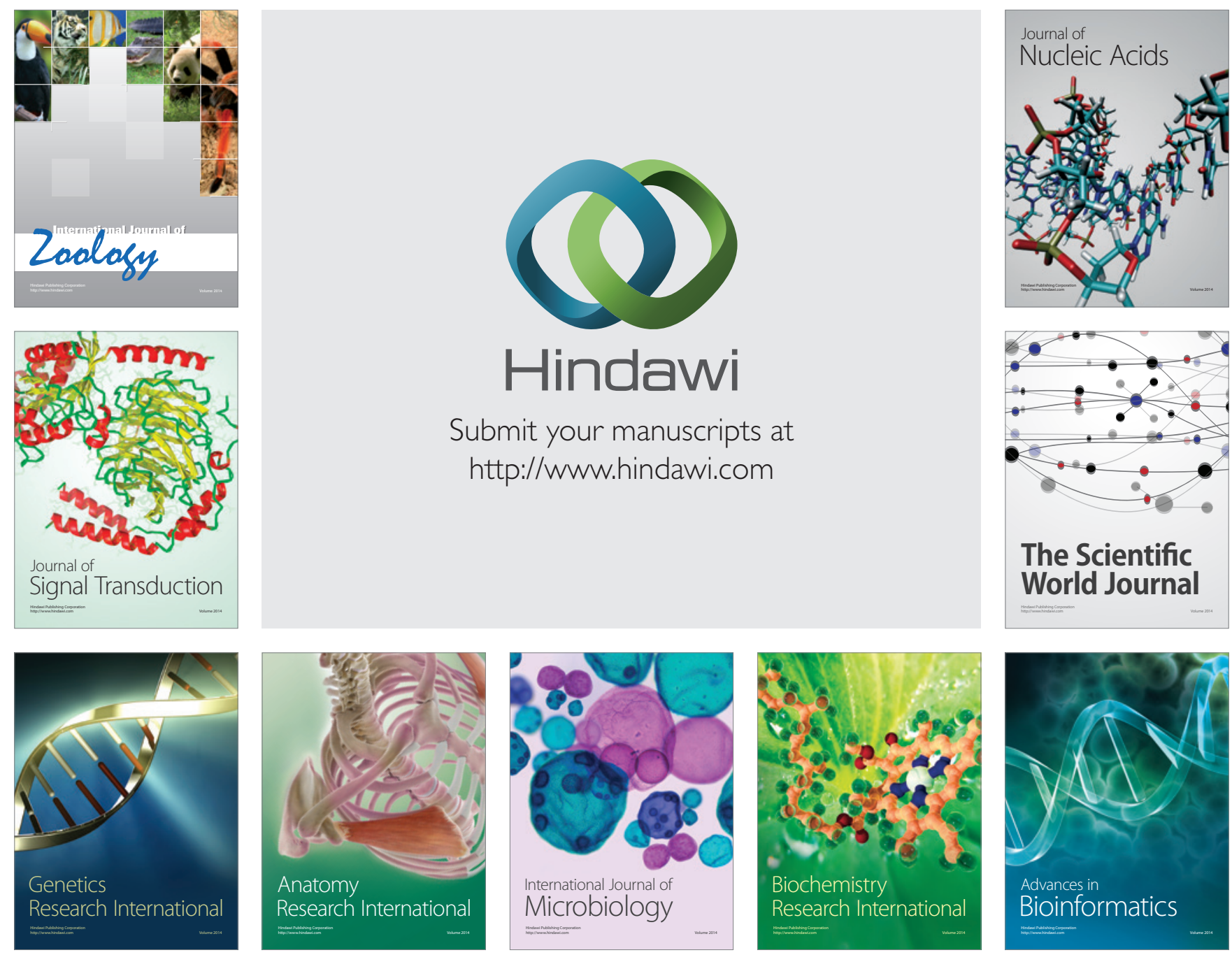

The Scientific World Journal
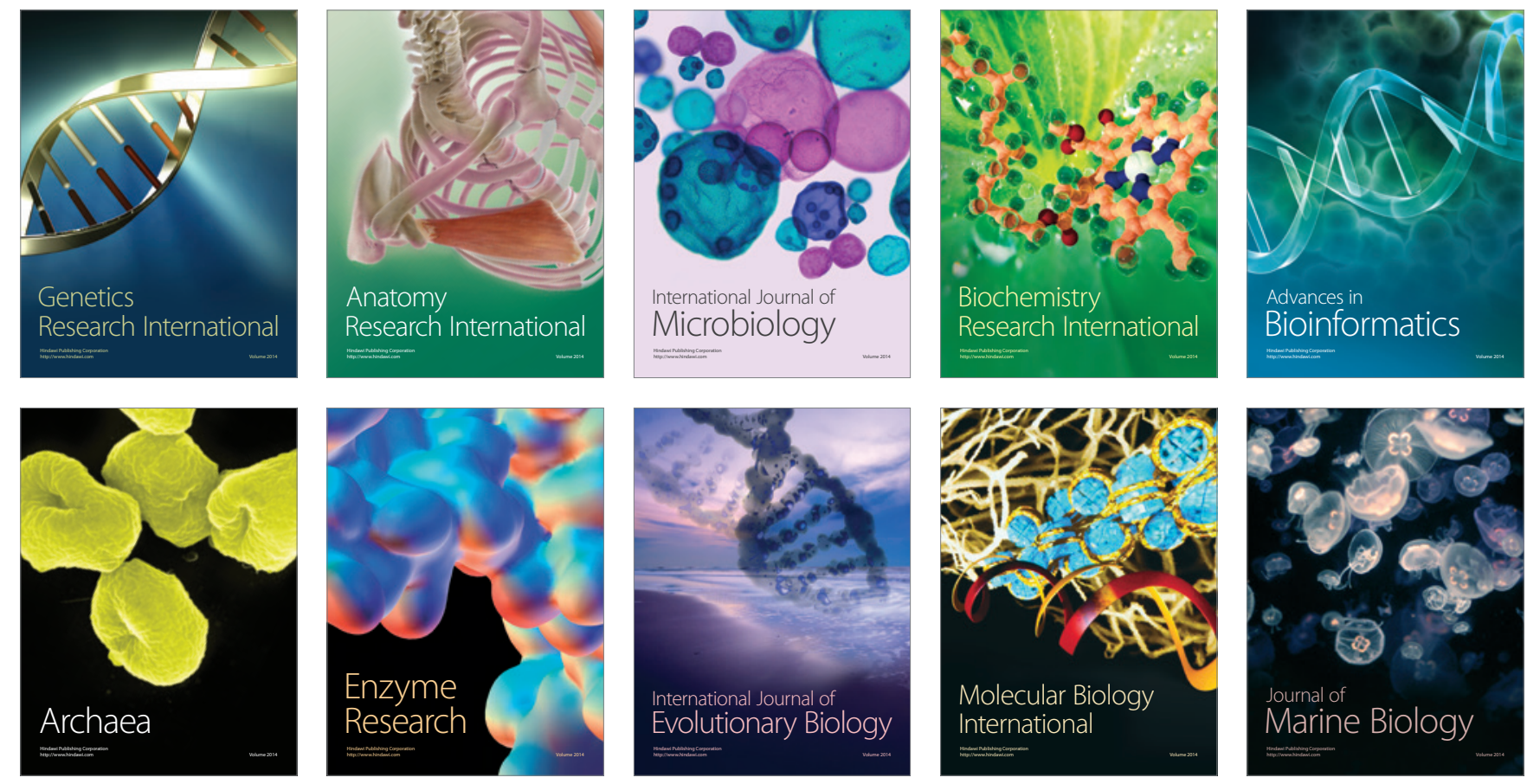